\title{
Acquisition of Pronominal Clitics in Romanian*
}

\author{
Maria Babyonyshev \\ Stefania Marin \\ Yale University. Department of Linguistics \\ P.O. Box 208366, New Haven, CT 06520-8366, USA \\ maria.babyonshev@yale.edu \\ stefania.marin@yale.edu
}

\begin{abstract}
This paper uses new evidence from elicited production experiments to establish that Romanian children do not omit either direct or indirect object clitics at a significant rate. The results reported for the acquisition of indirect object clitics are particularly significant in that, for the first time, it is possible to demonstrate the similarity between the acquisition of direct and indirect object clitics in Romanian and, arguably, for other languages that pattern with Romanian in the relevant respects. Furthermore, our findings receive a natural explanation if it is assumed that two conditions must be met for children to produce clitics. First, children's grammars must not be constrained by any relevant grammatical constraints, such as the Unique Checking Constraint (Wexler 1998, 2003). Second, children must be able to produce utterances of the length required by the clitic constructions. (137words)
\end{abstract}

Key words: first language acquisition, Romance languages, Romanian, accusative clitics, dative clitics, cross-linguistic variation.

\section{Table of Contents}

\section{Introduction}

2. Clitic constructions in Romanian

3. Clitic acquisition background

4. Explaining the existence of cross-linguistic variation in the clitic acquisition patterns

\section{Acquistion of direct object clitics} in Romanian
6. Acquisition of indirect object clitics in Romanian - Experiment 2

\section{Discussion}

Appendix I

Appendix II

References

* Acknowledgements: We would like to thank the audiences at the 34 LSRL, The Second Lisbon Meeting on Language Acquisition, 29 BUCLD, and Anna Gavarró, Vina Tsakali, Kenneth Wexler, and two anonymous reviewers for helpful comments on earlier versions of this work. The second author's work was partially supported by NSF grant BCS-9876456 to Yale University. 


\section{Introduction}

This paper is concerned with the acquisition of Romanian direct and indirect object clitics, illustrated in (1). On the basis of new experimental data, we demonstrate that object clitic constructions do not cause significant problems to young Romanian children, contrary to earlier claims made in the literature (Avram 1999). In addition, we demonstrate that a natural explanation for this pattern can be provided using the Unique Checking Constraint hypothesis (henceforth, UCC) developed in Wexler $(1998,2003)$. We argue that two conditions must be met for children to be able to produce object clitics: first, the clitic constructions in their grammars must not violate any relevant syntactic constraints, such as the UCC, and second, they must be able to produce utterances that are long enough to contain such clitics.
a. Elefantul
$l$ -
a
stropit
Elephant-the him-ACC- has sprinkled

'The elephant sprinkled him.'

b. Elefantul $l-\quad$ a stropit pe băiat

Elephant-the him-ACC- has sprinkled on boy

'The elephant sprinkled the boy.'

c. Moş Crăciun $i \quad$-a adus un cadou

Santa Claus him/her-D has brought a present

'Santa brought him/her a present.'

d. Moş Crăciun $i \quad$-a adus un cadou fetiţei

Santa Claus him/her-D has brought a present girl-the-D

'Santa brought the girl a present.'

Furthermore, we establish the existence of cross-linguistic variation with respect to the patterns of clitic acquisition, so that in some of the languages for which clitic acquisition has been studied, direct object clitic constructions are problematic for young children (this is the case for French, Italian, and Catalan), while in others, direct object clitic constructions do not cause problems (this is the case for Spanish, Greek, and - as we will demonstrate below - Romanian). A theory that has the UCC as one of its components can predict this variation, based on specific grammatical properties of the clitic constructions in the relevant languages.

Finally, we expand this line of research to include the acquisition of indirect object clitics, which have received little attention up to now, in any language. We show that clear and testable predictions are made regarding the acquisition of these elements as well. Specifically, given the grammatical properties of indirect object clitic constructions, indirect object clitics are predicted not to be problematic for young children, regardless of whether direct object clitics are problematic or not. The Romanian data presented below offer strong support for these predictions. 


\section{Clitic constructions in Romanian}

This section provides a brief description of the properties of Romanian direct and indirect object clitics relevant to the discussion below, with special emphasis on the properties that distinguish Romanian from the more familiar Romance languages.

As for direct objects, these elements can occur within two distinct constructions in Romanian. The direct object can surface as a complement of the preposition pe, in which case it has to be doubled by a direct object clitic, as shown in (2), or it can surface as a complement of the verb (without the preposition), in which case clitic doubling is ungrammatical, as shown in (3). ${ }^{1}$ Note that these two constructions are equally acceptable, and there are no meaning or register differences associated with them.

a. Elefantul 1- a stropit pe băiat/pe tigru

Elephant-the him-ACC- has sprinkled on boy /on tiger-M

'The elephant sprinkled the boy/the tiger.'

b. *Elefantul a stropit pe băiat/ pe tigru

Elephant-the has sprinkled on boy/ on tiger

(3) a. Elefantul a stropit băiatul/tigrul/gardul

Elephant-the has sprinkled boy-the/tiger-the/fence-the

'The elephant sprinkled the boy/tiger/fence.'

b. *Elefantul $l$ - a stropit baiatul/ tigrul

Elephant-the him-ACC- has sprinkled beetle-the/ tiger-the

It is important to note that when proper names act as direct objects only the clitic doubling construction remains possible, as shown in (4). In other words, a proper name direct object must be doubled by an accusative clitic and cannot occur without one, as the ungrammaticality of (5) demonstrates.
a. Elefantul $l$ -
a stropit
pe Dănuţ
Elephant-the him-ACC has sprinkled on Danny
'The elephant sprinkled Danny.'

$\begin{array}{llll}\text { b. *Elefantul a stropit pe Dănuţ } & \\ \text { elephant-the has } & \text { sprinkled } & \text { on Danny }\end{array}$

(5)
a. *Elefantul a stropit Dănuţ Elephant-the has sprinkled Danny
b. *Elefantul $l$ - $\quad$ a stropit Dănuţ Elephant-the him-ACC- has sprinkled Danny

1. Clitic doubling is not possible with inanimate objects. If the full DP object is present, only the construction in (3) is available; if the full DP object is not present, a simple clitic construction, such as the one shown in (1a), is available as well. 
As for indirect object constructions, clitic doubling is required for all dative arguments in Romanian, including Goals, Benefectives, and Possessives. This pattern is illustrated in (6) for a Goal argument. One potential complication that must be noted at this point is that verbs requiring a Goal, a Benefactive or a Possessive argument can be quite easily reanalyzed as two-argument verbs, in which case the dative argument (and hence the indirect object clitic) could be suppressed without causing ungrammaticality, as shown in (7). Note that in this example, there is a shift in meaning from a focus on the Goal argument in (6) to a focus on the action of «bringing presents» in (7).

a. Moş Crăciun $i$ -a adus un cadou fetiţei Santa Claus him/her-D has brought a present girl-the-D 'Santa brought the girl a present.'

b. Moş Crăciun $i \quad$-a adus un cadou la fetiţă Santa Claus him/her-D has brought a present to girl 'Santa brought the girl a present.'

c. Moş Crăciun il le -a adus un cadou Santa Claus him/her-D/ them-D has brought a present 'Santa brought him/her/them a present.'

\section{(7) Q: Ce a facut Moş Crăciun What has done Santa Claus 'What did Santa do?'}
A: A adus un cadou Has brought a present 'He brought a present.'

Several points need to be noted with respect to the placement of Romanian clitics. The indirect object clitics show the familiar placement pattern characteristic of most Romance languages, being preverbal except with gerund and positive imperative forms. The placement pattern of direct object clitics, however, exhibits certain noteworthy properties. In most cases, these clitics precede the verbs in the expected fashion, as shown in (8) for a sentence containing a present tense verb. ${ }^{2}$

(8) Elefantul $\hat{\imath} l \quad / o$ stropeşte pe băiat / pe fată Elephant-the him-ACC/ her-ACC sprinkles on boy / on girl 'The elephant is sprinkling the boy/the girl.'

2. With the exception of the pattern illustrated in (9), direct object clitics in Romanian follow the general Romance pattern, being preverbal except with gerund and positive imperative forms, where they are post-verbal. 
However, for past tense verbs that utilize the auxiliary HAVE, the pattern is more complex, as demonstrated in (9). Although most pronominal clitics precede the auxiliary verb (see (9a)), the accusative $3^{\text {rd }}$ person singular feminine clitic follows the lexical verb (see (9b)). While a theoretical account of this pattern is beyond the scope of this paper, the empirical facts are taken into consideration and controlled for in the design of the experiments and the discussion of child data. ${ }^{3}$
a. Elefantul $l$ -
/i- $\quad$ /le- 'The elephant sprinkled the boy/ the boys/ the girls.'
b. Elefantul a stropit- $o$ pe fată Elephant-the has sprinkled- her-ACC on girl 'The elephant sprinkled the girl.'

a stropit pe băiat/băieți/fete Elephant-the him-ACC/them-M/them-F-ACC has sprinkled on boy /boys /girls

Another fact that plays a crucial role in the discussion below is that Romanian shows no participle agreement with either direct (9) or indirect objects (6c). This is true for all clitic constructions, regardless of type of clitic or position of clitic (preverbal or postverbal). In this respect, Romanian clitics pattern with Spanish clitics, rather than with French or Italian ones.

With this description of the relevant properties of direct and indirect object clitics in place, we can turn to a review of the language acquisition results that will prove important to our study.

\section{Clitic acquisition background}

\subsection{Acquisition of direct object clitics}

Previous studies have described two distinct patterns of object clitic acquisition in different languages: one in which object clitics are problematic for young children (Pattern I), and one in which object clitics are unproblematic for young children (Pattern II). ${ }^{4}$ The pattern of acquisition that we refer to as Pattern I has been attributed to child French, Italian, and Catalan (see Bottari et al. 1993/94, Friedemann 1994, Guasti 1994, Hamman et al. 1996, Schaeffer 2000, etc). The pattern of acquisition that we refer to as Pattern II has been attributed to child Spanish and Greek (see Wexler et al. 2004, Lyzcskowski 1999, Tsakali and Wexler 2003).

Pattern I of clitic acquisition is observed when children's grammars are not capable of generating clitic constructions in the appropriate, adult-like form. This basic grammatical problem has a number of consequences, listed in (10).

3. An account of this pattern is provided in Marin (2004), where it is shown that this placement difference cannot be accounted for in syntactic terms, but rather, is due to morpho-phonological requirements on clitic combinations.

4. Not all of these studies recognize that more than one pattern of acquisition exists in this domain, that is, some of them view the pattern they are describing as the only possible one. 
(10) Pattern I characteristics (French, Italian, Catalan):

a. A high rate of object clitic omission in obligatory environments;

b. Late appearance of object clitics in natural production data;

c. Disproportionately high use of definite direct objects, utilized in place of the problematic clitic objects.

Pattern II of clitic acquisition is observed when children's grammars are capable of generating clitic constructions in the appropriate adult-like form. This ability manifests itself in a number of specific ways, listed in (11).

\section{(11) Pattern II characteristics (Spanish, Greek):}

a. A low rate of object clitic omission in obligatory environments;

b. Relatively early appearance of object clitics in natural production data;

c. Relatively low use of definite direct objects.

The contrast between Pattern I and Pattern II is illustrated very clearly by the results of the elicited production study of Wexler et al. (2004), summarized in Table 1. Because this study utilized the same experimental procedure to test children learning Catalan and Spanish, languages that show Pattern I of clitic acquisition and Pattern II of clitic acquisition, respectively, its results are particularly easy to interpret. As the numbers in Table 1 make clear, young Catalan-speaking children have problems producing object clitics in obligatory environments (producing only 11 out of 62 required clitics at the age of two, and 60 out of 86 at the age of three), but young Spanish children show no difficulty producing object clitics in the same contexts (producing 58 out of the required 64 clitics at the age of two and 78 out of 80 at the age of three). Similarly, young Catalan children show a high rate of object omission (omitting 49 out of 62 required clitics at the age of two and 19 out of 86 at the age of three), but young Spanish children show almost no object omissions in the same environments (omitting only 5 out of 64 clitics at the age of two and 1 out of 80 at the age of three). Lastly, only young Catalan children seem to produce full DP objects in place of the problematic direct object clitics (producing 2 full DPs at the age of two and 7 DPs at the age of three), ${ }^{5}$ while young Spanish children do not (producing $1 \mathrm{DP}$ at the age of two and $1 \mathrm{DP}$ at the age of three). These results offer compelling evidence for the existence of two distinct patterns of linguistic development in this domain.

The existence of these two distinct patterns is made evident by other elicited production experiments as well: thus, Italian children perform similarly to Catalan children (Schaeffer 2000), while Greek children perform similarly to Spanish children (Tsakali and Wexler 2003). Furthermore, these distinct patterns of acquisition are also discernible from naturalistic data available for French (Bottari et al.

5. Note that in other Pattern I languages the rate of full DP object production in clitic environments is typically higher (e.g., 14\% for Italian two-year-olds and 23\% for Italian three-year-olds), which leads us to suspect that some additional Catalan-specific constraint is responsible for the relatively low number of full DP productions in this language. 
Table 1. Direct object clitics in obligatory environments (Wexler et al. 2004).

\begin{tabular}{lccc}
\hline Catalan vs. Spanish & Direct object clitic & Full DP object & Object omission \\
\hline Catalan age 1-2 & $11 / 62$ & $2 / 62$ & $49 / 62$ \\
\hline Catalan age 3 & $60 / 86$ & $7 / 86$ & $19 / 86$ \\
\hline Catalan age 4-5 & $85 / 94$ & $4 / 94$ & $7 / 94$ \\
\hline Spanish age 2 & $58 / 64$ & $1 / 64$ & $5 / 64$ \\
\hline Spanish age 3 & $78 / 80$ & $1 / 80$ & $1 / 80$ \\
\hline Spanish age 4 & $80 / 80$ & $0 / 80$ & $0 / 80$ \\
\hline
\end{tabular}

1993/4, Friedmann 1994, Hamman et al. 1996), Italian (Guasti 1994), and Spanish (Lyzcskowski 1999), although naturalistic production is less clear and easy to interpret due to the less controlled nature of this type of data collection.

\subsection{Acquisition of direct object clitics in Romanian: Previous Studies}

The first study to describe the acquisition of direct object clitics in Romanian is that of Avram (1999). In our terms, the main finding of this study is that early Romanian follows Pattern I, that is, object clitics are problematic for young children. Thus, at a time when the child's grammar is adult-like in most other respects, object clitics are omitted quite frequently, so that Romanian children are described as going through an optional clitic stage. Table 2 provides a summary of the results of this experiment. Clearly, the rate of object omission is quite high, so Avram's conclusion about the acquisition of clitic constructions in Romanian is understandable. However, two points that need to be noted in relation to these results make this conclusion appear less plausible.

First, the response rate is extremely low and the omission rate is quite high even for four and five year olds, which has not been observed in any language, whether Pattern I or Pattern II. This surprisingly poor performance shown even by the oldest children makes one wonder whether these unusual results are uncovering the real acquisition pattern or are a methodological artifact. Second, although Avram (1999) concludes that clitic omission by Romanian children is comparable to clitic omission by French and Italian children, the numbers reported in Table 2 suggest that the youngest Romanian children are significantly more successful than Italian or French children at producing clitics in obligatory environments. Thus, in comparing Romanian children (Table 2) with Italian children (Table 3), we can see that Italian two year olds omit object clitics in $64 \%$ of obligatory environments, but Romanian two year olds omit clitics in only $42 \%$ of such environments. ${ }^{6}$ This

6. In fact Avram's (1999) results for Romanian children are not comparable with Schaeffer's (2000) results for Italian at any age. Thus, while the Italian four year olds exhibit no clitic omissions (see Table 3), Avram's (1999) four year olds omit clitics 10\% of the time (see Table 2). Note also that variability in performance between children within the same age group is extremely high, which may suggest possible experimental confounds in Avram's (1999) study. 
Table 2. Direct object clitic omissions; CV - coefficient of variation (based on data from Avram 1999).

\begin{tabular}{lccc}
\hline Romanian & Overall omission & Average omission $(\mathbf{C V})$ & Response rate \\
\hline Age $2(2 ; 4, \mathrm{~N}=3)$ & $15 / 25$ & $42 \%(1.02)$ & $34 \%$ \\
\hline Age $3(3 ; 2, \mathrm{~N}=8)$ & $32 / 133$ & $25 \%(1.00)$ & $56 \%$ \\
\hline Age $4+(4 ; 3, \mathrm{~N}=5)$ & $7 / 56$ & $10 \%(1.70)$ & $44 \%$ \\
\hline Total $(3 ; 4, \mathrm{~N}=16)$ & $54 / 214$ & $24 \%(1.13)$ & $48 \%$ \\
\hline
\end{tabular}

Table 3. Object clitics in obligatory environments; elicitation (Schaeffer 2000).

\begin{tabular}{lccc}
\hline Italian & Object clitics & Full DP object & Omissions \\
\hline 2 year olds & $22 \%$ & $14 \%$ & $64 \%$ \\
\hline 3 year olds & $62 \%$ & $23 \%$ & $15 \%$ \\
\hline 4 year olds & $89 \%$ & $11 \%$ & $0 \%$ \\
\hline 5 year olds & $91 \%$ & $9 \%$ & $0 \%$ \\
\hline
\end{tabular}

difference is quite mysterious if we assume that Romanian is a Pattern I language. Thus, the results are unexpected for both the younger children and the older children, being surprisingly good and surprisingly bad, respectively. Moreover, they do not form a natural sequence, which could be produced by either a uniformly delayed acquisition pattern (as in French and Italian) or a uniformly early and unproblematic acquisition pattern (as in Spanish and Greek). Therefore, the results of this experiment did not appear to us to be conclusive or to form a clear and interpretable pattern and we felt that the acquisition of Romanian clitics deserved closer scrutiny.

\subsection{Acquisition of indirect object clitics}

While the acquisition of direct objects has been examined extensively in a number of languages, within both natural speech and elicited production studies, much less is known about the acquisition of indirect object clitics. To our knowledge, all studies on this topic are based on data from different varieties of Spanish, and many of them rely on analyses of natural speech corpora, rather than elicitation experiments.

The available studies seem to suggest that children acquiring Spanish have no particular problems with indirect object clitics. Thus Lyzckowski (1999), who analyzed the natural speech of three monolingual Spanish children available on CHILDES, found that indirect object clitics were produced fairly early (with the earliest point of production being 1;7, similarly to the direct object clitics) and were not omitted in obligatory environments, to the extent that it was possible to determine this through corpus analysis, so that the reported omission rate was less than $1 \%$. Similarly, Wexler and Torrens (2000), who examined the production of cli- 
tics within clitic doubling environments in the natural speech data of a monolingual Spanish child aged $1 ; 7$ to $3 ; 11$, discovered that dative clitics were produced without problems, with 23 clitics being produced within 24 obligatory environments. In addition, Blasco (2000) used an elicited imitation task to examine the production of dative and accusative clitics in simple clitic constructions and clitic doubling constructions by Spanish speaking children aged 1;9-2;10 and 2;2-2;10, respectively. When describing her findings, she states that at the earliest ages, 1;9$1 ; 10$, clitics were omitted $17.7 \%$ of the time, with omissions decreasing to $4.5 \%$ by the age of $2 ; 1$, and disappearing altogether after the age of $2 ; 2$. Although no separate analysis of dative clitics was carried out, Blasco does note that children's performance was similar for dative and accusative clitics, so that we can conclude that for the Spanish children examined in her study, dative clitics were produced freely after the age of 2;1. Finally, Anderson (1998) reports on the only elicited production experiment that has been carried out on Spanish indirect object clitics to date. Given the focus of the paper and the way the data are presented, it is impossible to know what the patterns of the dative clitic production are for $32 \%$ of the children that participated in the study. However, the author does state that at least $68 \%$ of the 40 children tested (aged $2 ; 0-3 ; 10$ ) show perfect use of all pronominal clitics, including indirect object ones.

Thus, the admittedly rather sparse evidence on the acquisition of indirect object clitics suggests that they are not problematic and are produced freely in obligatory environments, at least by children acquiring Spanish. In our terms, Spanish appears to be a Pattern II language both in the domain of direct object clitic acquisition and in the domain of indirect object clitic acquisition.

\section{Explaining the existence of cross-linguistic variation in the clitic acquisition patterns}

This section provides an overview of the theory utilized below to explain the existence of cross-linguistic variation in the clitic acquisition patterns and describes the predictions this theory makes for the languages discussed in the previous section.

The theory is based on the UCC Hypothesis, originally developed to deal with the Optional Infinitive stage of language acquisition (Wexler, 1998, 2003) and subsequently extended to handle the acquisition of clitic constructions (Wexler et al 2004, Tsakali and Wexler 2003). The UCC Hypothesis, given in (12a), states that, at the relevant stage of linguistic development, the grammar does not permit nominal elements (DPs) to check their DP features against more than one functional element. In other words, a nominal is not permitted to move through more than one functional projection in the course of the derivation within early grammars. The principle of Minimize Violations (MV), given in (12b), determines which derivations will be considered grammatical, stating that the derivation that violates the least number of grammatical principles (such as the UCC or the EPP) has to be pursued. Thus, the MV allows selection of the structure associated with the fewest violations or it allows optionality, in case the two constructions under consideration violate an equal number of principles. 
(12) a. Unique Checking Constraint (UCC):

The D-feature of DP can only check against one functional category.

b. Minimize Violations (MV)

Given an LF, choose a numeration whose derivation violates as few grammatical properties as possible. If two numerations are both minimal violators, either one may be chosen.

[Wexler 1998: 59]

Let us see how this framework applies to the object clitic constructions under consideration. We adopt the analysis of clitic constructions developed in Sportiche (1996), within which accusative clitics are derived as shown in (13):

(13) a. base-generated structure:

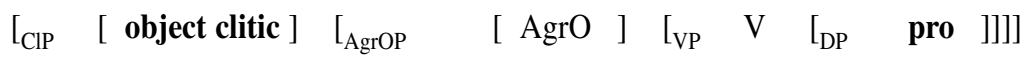

a. surface structure of a language with participle agreement (e.g.,French, Italian):

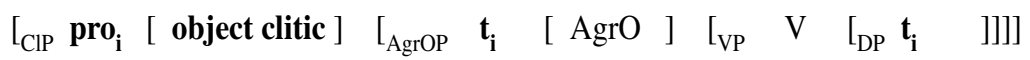

b. surface structure of a language without participle agreement (e.g., Spanish):

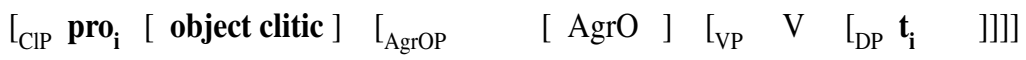

Under this analysis, the object clitic is base-generated as a head of a functional projection referred to as CIP in the diagram above. Another element, the associate of the clitic, is generated in the direct object (complement of the verb) position and has to undergo raising to the position of [Spec, $\mathrm{ClP}]$ in the course of the derivation, where it has to enter into a feature-checking relation with the clitic. In simple clitic constructions, the clitic associate is a pro which undergoes overt movement to $\mathrm{ClP}$ and in constructions with clitic doubling, the clitic associate is an overt DP which undergoes cover movement to this position.

Crucially, in languages with participle agreement, the pro associate has to move through the Specifier of AgrOP on its way to ClP (for justification, see Kayne 1989). This means that this nominal must move through two functional projections (CIP and AgrOP), checking its D-feature against two functional elements (AgrO and $\mathrm{Cl}$ ) and thus violating the UCC. In contrast, in languages lacking participle agreement, the pro associate does not move through the Specifier of AgrOP on its way to CIP. Thus, it moves through only one functional projection (ClP), checking its D-feature against only one functional element $(\mathrm{Cl})$ and not violating the UCC.

At the stage of development where the grammars are constrained by the UCC, children acquiring languages with participle agreement will be forced to deviate from adult grammars in one of two ways: either omitting the ClP (and, therefore, the clitic) or omitting the AgrOP, which will produce a caseless pro and, most likely, crash the derivation. A further option available to them is to choose to utilize a different construction, one containing a full DP object, rather than a clitic with an 
associate. Although this choice will result in a derivation that does not violate the UCC or any other principle of grammar, it will force the child to use a construction that is not appropriate, given the discourse and the conversational context. In contrast, children acquiring languages without participle agreement will not be forced to deviate from adult grammars and will be able to produce clitic constructions when required.

Crucially, this approach also makes explicit predictions regarding the acquisition of the indirect object clitic constructions. Given our syntactic assumptions, the derivations containing dative clitics are parallel to those containing accusative clitics, as shown in (14). Thus, the dative clitic is base-generated as a head of ClP, with the associate of the clitic being base-generated in a VP-internal position and subsequently undergoing raising to the position of [Spec, $\mathrm{ClP}]$. Just as before, the clitic associate may be a pro which undergoes overt movement to ClP (this produces the simple clitic construction) or an overt DP which undergoes cover movement to this position (this produces the clitic doubling construction). An important difference between direct object clitics and indirect object clitics is that while the former are able to trigger object agreement in some languages, the latter do not seem to be able to do so in any of the languages under consideration (or any other human language, for that matter). Within our syntactic framework this means that the associate of the indirect object clitic does not move through the Specifier of AgrIOP on its way to ClP. In other words, it moves through a single functional projection (CIP), checking its D-feature against a single functional element $(\mathrm{Cl})$ and not violating the UCC. ${ }^{7}$ As a result, children acquiring the languages under consideration will be able to produce indirect object clitic constructions in the appropriate adult-like fashion, even at the stage of development when their grammars are constrained by the UCC, a stage at which production of the direct object clitics may be problematic.

(14) a. base-generated structure:

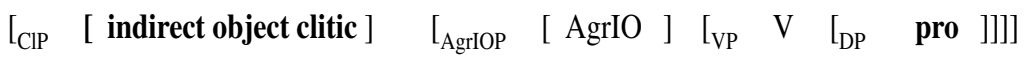

b. surface structure:

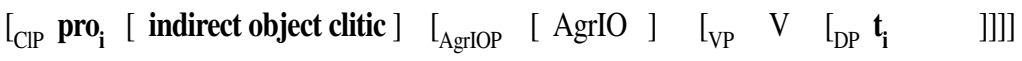

To conclude, based on the UCC Hypothesis, we expect direct object clitics to be problematic in languages that show participle agreement, such as French, Italian, and Catalan. However, we expect direct object clitics to be unproblematic in languages without participle agreement, such as Spanish, Greek, and Romanian. Furthermore,

7. As an anonymous reviewer points out, the same predictions would follow from a slightly different set of syntactic assumptions as well: if we assume that AgrIOP is not involved in checking the case features of indirect object clitics at any point in the derivation (or even that AgrIOP does not exist), it is still true that the dative clitic only moves through a single functional projection (ClP). Thus, our predictions do not depend on a specific syntactic framework in this domain and our choice to utilize AgrIOPs was made only for the sake of explicitness. 
we expect indirect object clitics to be uniformly unproblematic across languages. Note that although most of these expectations are fulfilled, the acquisition pattern attributed to early Romanian in Avram (1999) is in conflict with the predictions of this theory. In the next section, we investigate and resolve this discrepancy.

\section{Acquisition of direct object clitics in Romanian}

\subsection{Experiment 1}

Given the theoretical predictions made with respect to the acquisition of pronominal clitics in Romanian and the mixed results of previous research (Avram 1999), the main goal of our first experiment was to study the acquisition of object clitics in early Romanian in a systematic and thorough fashion, examining a range of distinct environments and conducting the experiment with a large number of children, thus addressing potential confounds in previous research.

\subsubsection{Materials and subjects}

The current study included a large number of distinct conditions (8), with 4 tokens of each condition, which resulted in a total of 32 elicitation stories, each containing a different obligatorily transitive verb. These conditions are summarized in Table 4. The independent variables were the tense of the question/target sentence (past tense vs. present tense), the gender of the direct object (feminine vs. masculine), and the type of direct object (definite DP vs. proper name). We were interested in manipulating the tense and gender of the object clitic in the anticipated response because the position of feminine clitics in past tense utterances is distinct from the position of all other clitics (see section 2 for discussion). In addition, by including target sentences with proper name objects, we introduced environments in which a clitic of some kind is obligatory: in these conditions, an appropriate response could be either a simple clitic construction or a construction in which a proper name object is doubled by a clitic (see section 2 for description). Thus, we had an opportunity to compare structures in which using a clitic is optional in syntactic terms, although obligatory in discourse terms (i.e., the definite DP conditions), with structures in which using the clitic is obligatory in both syntactic and discourse terms (i.e., the proper name conditions).

The experiment utilized a single elicitation task, based on Schaeffer (2000) and modified to accommodate the properties of Romanian clitic constructions. An example of the elicitation procedure is given in (15). In this task, the experimenter

Table 4. Summary of conditions.

\begin{tabular}{lcccc}
\hline & \multicolumn{2}{c}{ Definite DP } & \multicolumn{2}{c}{ Proper Name } \\
\hline & Feminine & Masculine & Feminine & Masculine \\
\hline Present & $4(\mathrm{o})$ & $4(\hat{1})$ & $4(\mathrm{o})$ & $4(\hat{l})$ \\
\hline Past & $4(-\mathrm{o})$ & $4(1-)$ & $4(-\mathrm{o})$ & $4(1-)$ \\
\hline
\end{tabular}


uses props to act out a simple story in front of the child, describing what is happening without using the target construction. After the description is completed, the experimenter asks the child to explain what happened to a puppet that was present but not paying attention. This procedure was successful $81 \%$ of the time (compared to $48 \%$ in Avram's study). ${ }^{8}$

\section{(15) Model elicitation - Past masculine definite DP}

Exp: 'Look what else I have here, a bad dinosaur and a snake and look, the snake is swallowed, he is in the dinosaur's mouth.'

Ce i- a făcut dinozaurul la şarpe?

What him-D has done dinosaur-the to snake?

'What did the dinosaur do to the snake?'

Child 2;4: L- a- nghiţit

him-ACC- has swallowed

'He swallowed/ate him.'

The experiment was conducted with 25 monolingual Romanian children, aged $2 ; 0-3 ; 10$, recruited from two Romanian kindergartens in a Southeastern Transylvanian city. They were audiorecorded on a digital SONY Minidisc recorder. The experiment was conducted in a kindergarten classroom, either in a separate room or in a quiet corner of the common room if a spare room was not available.

As Table 5 shows, the children were grouped both according to age and $\mathrm{MLU}_{\mathrm{W}}$. Because minimal well-formed words in Romanian often include more than one morpheme (e.g. fetiţ $+\breve{a}$ 'girl' - fetiț $+a$ 'the girl', *fetiţ), the MLU was calculated in terms of words, rather than morphemes. Note that word-based MLU has been independently proposed as a more reliable, effective, and theoretically preferable measure, since no ad hoc decisions have to be made as to what constitutes a word, while a definition of morphemes is both theory-driven and ad hoc, especially in child language (cf. Arlman-Rupp et al. 1976, Hickey 1991). ${ }^{9}$ To calculate $\mathrm{MLU}_{\mathrm{W}}$,

8. Here are some of the potential confounds that were addressed in our experiment, which, we believe, contributed to the significant increase in the response rate. First, Avram's experiment had few conditions and few tokens of each condition, with some conditions consisting only of questions relying on children's previous knowledge of specific fairy-tales. Second, the experiment tested only a small number of children, e.g., 3 two year olds and 7 three year olds. Third, the format of the question used to elicit the clitic constructions was What did $X$ do with $Y$, which in our pilot study was shown to elicit intransitive responses in both children and adults, thus producing a syntactic and discourse environment in which direct object clitics are optional, rather than obligatory. The question we utilized: What did $X$ do to Y? was shown by the pilot experiment to result in more transitive responses and made our study comparable to other cross-linguistic studies, which all used a question of the type What did $X$ do to $Y$ ? (see Babyonyshev and Marin, to appear, for a more detailed description of this).

9. Note that in these studies, as well as those that rely on the methodology developed in them, «word» is understood as a lexical word, rather than a prosodic word. We followed the established procedure in this field and, hence, a clitic and its host are counted as two words. 
Table 5. Description of subjects - Experiment 1.

\begin{tabular}{lccccc}
\hline & Age range & Mean age & Boys & Girls & Total \\
\hline Age 2 & $2 ; 0-2 ; 11$ & $2 ; 5$ & 5 & 7 & 12 \\
\hline Age 3 & $3 ; 4-3 ; 10$ & $3 ; 6$ & 3 & 10 & 13 \\
\hline$<2 \mathrm{MLU}_{\mathrm{W}}$ & $2 ; 0-3 ; 5$ & $2 ; 7$ & 5 & 2 & 7 \\
\hline$>2 \mathrm{MLU}_{\mathrm{W}}$ & $2 ; 4-3 ; 10$ & $3 ; 3$ & 3 & 15 & 18 \\
\hline
\end{tabular}

only sentences that did not contain clitics (and should not have contained clitics) were used.

\subsubsection{Results and discussion}

In this section we report the results of the experiment, noting both the more general and the more specific patterns evident from the data. Table 6 gives the results, in raw overall numbers and in average percentages across children, broken down by the age of the subject (two year olds vs. three year olds) as well as by the $\mathrm{MLU}_{\mathrm{W}}$ of the subject $\left(\mathrm{MLU}_{\mathrm{W}}<2.0\right.$ vs. $\left.\mathrm{MLU}_{\mathrm{W}}>2.0\right){ }^{10}$

An examination of the results reported in Table 6 leads to several conclusions. First, it is clear that the rate of clitic production for three year olds, i.e., 93\%, is typical of Pattern II languages, where object clitics are not problematic, rather than Pattern I languages, where object clitics cause problems (c.f. $62 \%$ rate of clitic production found by Schaeffer 2000 for Italian three year olds). ${ }^{11}$ Second, the rate of clitic production for two year olds, i.e., $38 \%$, is more difficult to interpret. On the one hand, it is far below the (nearly perfect) performance expected for children acquiring a Pattern II language, but on the other hand, it is also drastically better than

Table 6. Overall results - Experiment 1 .

\begin{tabular}{lllllll}
\hline Romanian & \multicolumn{2}{c}{ Direct object clitic } & \multicolumn{2}{c}{ Full DP object } & \multicolumn{2}{c}{ Object omission } \\
\hline Age $2 \mathrm{~N}=12$ & $94 / 193$ & $38 \%$ & $3 / 193$ & $2 \%$ & $96 / 193$ & $60 \%$ \\
\hline Age $3 \mathrm{~N}=13$ & $361 / 387$ & $93 \%$ & $2 / 387$ & $0.5 \%$ & $24 / 387$ & $6.5 \%$ \\
\hline$<2 \mathrm{MLU}_{\mathrm{W}} \mathrm{N}=7$ & $25 / 104$ & $16 \%$ & $1 / 104$ & $2 \%$ & $78 / 104$ & $82 \%$ \\
\hline$>2 \mathrm{MLU}_{\mathrm{W}} \mathrm{N}=18$ & $430 / 476$ & $86 \%$ & $4 / 476$ & $1 \%$ & $42 / 476$ & $13 \%$ \\
\hline
\end{tabular}

10. Two points relevant to our counting procedure should be noted here. First, in cases where children produced more than one response, if a child corrected herself without interruption from the experimenter, the correct answer was used for the counts, but if such correction occurred after experimenter's intervention, the very first answer was counted. Second, in cases where the target verb was not used in the child's answer, the response was included in the counts if it contained a verb that required a direct object, similarly to the target verb. In other words, purely lexical errors did not affect our analysis.

11. Note that the three adult controls used in this experiment produced direct object clitics $100 \%$. 
the performance of the two year olds acquiring a Pattern I language: thus, the $38 \%$ production rate observed in the Romanian data is nearly twice as high as the $22 \%$ production rate reported by Schaeffer (2000) for Italian two year olds.

Postponing a discussion of this pattern for now, let us turn to another notable pattern apparent in the results: full DP responses are extremely low for both age groups, drastically lower than those produced by children learning Pattern I languages. Thus, Romanian two year olds produce full DP objects $2 \%$ of the time, while Italian two year olds produce full DP responses $14 \%$ of the time; Romanian three year olds produce full DP objects $0.5 \%$ of the time, while Italian three year olds produce full DP objects $23 \%$ of the time. Clearly, Romanian children are not using the strategy of producing the inappropriate DP response to avoid the problematic clitic constructions. Thus, this diagnostic suggests that Romanian is behaving as a Pattern II language, as well.

In light of these two points, how should we interpret the response pattern produced by the two year old subjects in our experiment? To arrive at an explanation of their mixed and not particularly clear-cut pattern of responses, we need to consider the fact that this group of subjects is very young. Crucially, many of the children in this group are not capable of producing utterances of the length required to contain an object clitic. Recall that a present tense utterance containing a clitic must be at least two words long and a past tense utterance containing a clitic must be three words long (see Section 2 for discussion). ${ }^{12}$ If a child's performance is constrained by a production limitation that does not allow her to produce utterances that are at least two words long, then the clitic constructions will not be produced, regardless of whether the grammar is capable of generating the relevant constructions or not.

To test this hypothesis, we need to examine the patterns of clitic production for the groups defined by their MLU, rather than age. Given our approach, we expect children with MLU less than 2 to show a low rate of clitic production, and children with MLU greater than 2 to show a high rate of clitic production. As the results reported in Table 6 demonstrate, this is exactly the pattern that is observed: children with MLUs less than 2 produce object clitics at the rate of $16 \%$, while children with MLUs greater than 2 produce object clitics at the rate of $86 \%$. Thus, we can conclude that Romanian is a Pattern II language, within which children produce object clitics freely as soon as they are able to produce utterances that are long enough to contain them. ${ }^{13}$

12. Depending on the precise morpho-phonological assumptions, past tense utterances containing a verb, an auxilliary and a clitic can be considered as either two-word or three-word utterances. Hence we have made the conservative choice of maintaining the MLU cutoff at two words for all clitic constructions: the children whose MLU is below two should have problems producing past tense clitic utterances, regardless of whether they are analyzed as two-word utterances or threeword utterances.

13. As an anonymous reviewer points out, a strong argument for our proposal could be made on the basis of a comparison between the pattern of clitic production shown by Romanian children with low MLUs and that of children with low MLUs who are acquiring other Pattern II languages (e.g., Spanish, Greek). While we agree with the reviewer, unfortunately, there is no available information 
Note that our approach also explains why Romanian children do not use full DP answers as a strategy to avoid clitic constructions. Because their clitic omission is due to production limitation rather than to a grammatical constraint, providing a full DP answer is not an option that allows the children to avoid the problem they are dealing with. Production limitations will force the children to omit any element (either a clitic or a full D) whose presence increases the length of the utterance past the accessible limit.

Let us now briefly touch on some of the more fine-grained patterns shown by the data, addressing the question of whether young children show a preference for a specific gender of clitic, type of direct object, or tense of clitic utterance. Turning to the gender of the clitic first, for the two year old group, we see more correct feminine clitic productions than masculine clitic productions ( $46 \%$ feminine vs. $25 \%$ masculine), although there is no general bias towards responding more to feminine conditions (55\% of total responses were feminine and $45 \%$ were masculine). No gender preference is shown by the three year old group. These findings demonstrate that young children are doing better with feminine clitics than masculine clitics, even though the placement of feminine clitic is less uniform than the placement of masculine clitics (see Section 2 for discussion). This leads us to conclude that position of clitic plays no role in the production patterns exhibited, and that acquisition proceeds in the same manner with either pre-verbal or postverbal clitics. Regardless of the position of the clitics, Romanian children are successful in producing them, as predicted by the theory embraced in this paper.

With respect to the tense of the target utterance, for the two year old group, we see more responses in the present tense than the past tense (64\% present vs. $37 \%$ past), although there is no difference in the rate of correct responses with respect to tense ( $40 \%$ correct present vs. $35 \%$ correct past). Once again, no preference is shown by the three year old group. These findings suggest that young children have a preference for present tense utterances independent of the nature of the clitic task. This shows that the acquisition of clitics and tense are not related within citic constructions, given that children perform equally well with both present and past tense.

Finally, no group of children exhibited a preference for proper name direct objects as opposed to common noun direct object. Neither was there a difference in the correct response rate based on object type. This demonstrates that Romanian children produce clitics equally successfully in syntactically obligatory and optional environments, just as we would expect if clitics do not cause any problems for these children. In more general terms, we find that although individual children might show a preference for a specific gender, tense, or type of object, the direction of preference is not consistent across children.

on the MLUs of the children who had participated in the relevant studies, which makes such a direct comparison impossible. Because MLUs and age are highly correlated (see Templin 1957), a comparison of closely matched age groups can be quite informative; however, this correlation is not perfect and, as a result, an age-based comparison can miss the MLU-based pattern discussed above. 
To sum up, the results of our experiment show that early Romanian is a Pattern II language, i.e., that object clitics are not problematic for young children, being produced freely in obligatory environments, exactly as predicted by the UCC Hypothesis. Clitic omissions shown by very young children in this language are not comparable to those observed in Pattern I languages. As we have argued, they are not triggered by grammatical constraints (such as the UCC), but rather, are due to production limitations of children who are not yet capable of producing utterances of the length required by the clitic constructions. Although the main findings of the study are quite striking and convincing, it does have one limitation that needs to be addressed. Specifically, it did not include a separate task for collecting utterances that could be used for $\mathrm{MLU}_{\mathrm{W}}$ calculation. As a result, for some children $\mathrm{MLU}_{\mathrm{W}}$ was calculated on rather few available independent utterances. To address this problem we designed two follow-up studies, which included different types of pretests intended to gather data that could be used for an independent calculation of $\mathrm{MLU}_{\mathrm{W}}$ (for a more detailed description see Babyonyshev and Marin 2004a,b). The pretests utilized a narrative task, within which children were asked to construct a story based on a picture book, and an elicited imitation task, within which children were asked to repeat utterances of a short story (consisting of 25 utterances, ranging from 6 to 12 words per utterance, 5.5 words per utterance on average). ${ }^{14}$ Unfortunately, the follow-up studies did not turn out to be as informative as they could have been, because all of the participants (aged 2;4 - 3;11) happened to have MLUs that were greater than 2 according to the calculation procedure which we generally found most helpful (see footnote 14). Nonetheless, these studies did demonstrate very clearly that Romanian children with MLUs greater than 2 are capable of producing clitics in obligatory environments, regardless of their age group.

\section{Acquisition of indirect object clitics in Romanian - Experiment 2}

While the acquisition of direct object clitics has been studied quite extensively in a number of languages, the acquisition of indirect object clitics remains virtually unexamined, especially with experimental techniques. As pointed out in Section 4 , the patterns of indirect object clitic acquisition are of great theoretical interest, given the predictions made by our approach in this area. This section presents the results of an elicited production experiment which tested young Romanian children's production of both direct and indirect object clitics. While the portion of the experiment that elicited direct object clitics was carried out mainly to replicate our previous findings, the portion of the experiment that elicited the indirect object

14. We used two slightly different procedures to calculate the MLUs in the studies: a more conservative procedure, in which all utterances that the children could have produced were included in the calculation of their MLU (if the child did not produce a given utterance, it was considered to contain 0 words), and a more liberal procedure, in which only the utterances which the children actually produced were included in the calculation of their MLU. The use of the first procedure resulted in a lower estimate of the MLUs than the use of the second one. The second procedure is more comparable to the MLU calculations based on natural speech production and, hence, was used for the MLU calculations reported in this paper. 
clitics constituted the first attempt to examine the acquisition of indirect object clitics in a fairly extensive elicitation setting. ${ }^{15}$

\subsection{Materials and subjects}

This experiment included two pretest tasks designed to collect a sample of speech sufficient for $\mathrm{MLU}_{\mathrm{W}}$ calculation: a story-telling task using a story book, Carl's Afternoon in the Park (Day, 1991), and an elicited imitation task (see section 5.1.3.). Separate $\mathrm{MLU}_{\mathrm{W}}$ values were calculated from the data obtained in the two pretests; they were then averaged to one value that was used as an $\mathrm{MLU}_{\mathrm{W}}$ index for each child. ${ }^{16}$

Direct object clitics were elicited using the same procedure as in Experiment 1, with a subset of the stories employed in those experiments being used here. Specifically, as shown in Table 7, each child was presented with 10 stories that elicited masculine and feminine direct object clitics in the past tense. Past tense was chosen for the sake of uniformity with the indirect object task. Note that in this experiment, the referent of the clitic was always a common noun, rather than a proper name.

To collect indirect object clitics, this experiment used 21 stories designed to elicit 3rd person singular dative clitics in sentences containing the past form of a verb requiring an obligatory Goal, Benefactive, or Possessive dative argument (Table 7). The referent of the clitic was a common noun that was either masculine or feminine in gender (recall that there is no gender differentiation for indirect object clitics). Also, because the position of indirect object clitics does not change as a function of tense, we elicited only past tense responses, which were previously found to be easier to demonstrate.

Indirect object clitics were elicited using a procedure similar to that of Experiment 1, but with slight modifications, required to accommodate the specific properties of the indirect object construction. As illustrated in (16), after a short story was acted out in front of a child, she was asked to tell the puppet what had happened. A sequence of two question types was used. First, the experimenter used

Table 7. Summary of conditions - Experiment 2.

\begin{tabular}{lcc}
\hline & Feminine full DP Past & Masculine full DP Past \\
\hline Direct object clitic & $5(-\mathrm{o})$ & $5(1-)$ \\
\hline Indirect object clitic (Goal ) & $4(\mathrm{i}-)$ & $3(\mathrm{i}-)$ \\
\hline Indirect object clitic (Possessive) & $5(\mathrm{i}-)$ & $2(\mathrm{i}-)$ \\
\hline Indirect object clitic (Benefactive) & $3(\mathrm{i}-)$ & $4(\mathrm{i}-)$ \\
\hline
\end{tabular}

15. Anderson (1998) is based on an elicited production experiment that includes some dative clitics as well, but because her focus is not on clitic production as such, but rather on the acquisition of distinctive case in pronominal forms, her results cannot be used to shed light on the patterns of indirect object clitic acquisition.

16. This averaging was necessary because some of the children refused to perform one (or the other) of the tasks, so that no single task could be used to derive an MLU index for all children. 
a question exemplified in Step 1 in (16). Although this is not the most appropriate type of question to use in this context, because it can reduce the prominence of the Goal/Benefactive/Possessive argument, we chose it to avoid using the dative argument, whose presence would require clitic doubling and, thus, the occurrence of the dative clitic within the question. If the child produced an answer containing the dative clitic construction, the experimenter would move to the next experimental item. However, if the child produced no answer to this question, or produced an answer that contained a verb that does not require a Goal, Benefactive, or Possessive argument, the experimenter followed up with the second question type, exemplified in Step 2 in (16). Although this question format contained the targeted clitic, it was more felicitous, because it made the Goal/Benefactive/Possessive argument salient in the story. Crucially, questions of this form were not used to cue children if the first response they provided contained a verb requiring the presence of a clitic, but did not contain the clitic. Thus, this question format was used only as a means of boosting the response rate, which was extremely low in our pilot experiments, and reinforcing the prominence of the Goal/Benefactive/Possessive argument. We suspect that the form of the question employed in Step 1 diminishes the importance of the dative argument in the story, since the four adult controls who were tested in the pilot study with this question format provided the expected verb without a dative clitic $11 \%$ of the time.

(16) Indirect object model elicitation story

Exp: 'This girl has a birthday party and now this boy comes with a present. Look what happens now. The girl has a present.'

Step1: Ce a facut baietelul de are fetita un cadou? What has done boy-the that has girl-the a present 'What did the boy do so the girl has a present?'

Child: $i$ - a dat un cadou

Him/her-D has given a present

'He gave her a present.'

Step 2: Ce $i-\quad$ a facut baietelul la fetita de are uncadou What her-D has done boy-the to girl that has a present

'What did the boy do to the girl so she has a present?'

Child 2;6: $i$ - a dat cadou Him/her-D has given present 'He gave her a present.'

The experiment was conducted with 18 monolingual Romanian children aged between 2;5 and 3;10 (see Table 8 for detailed description of the subjects). ${ }^{17}$ The

17. One additional subject aged 3;2 was excluded because of pronunciation problems that made his speech difficult to interpret. The articulatory problems he was exhibiting are not typical for Romanian children at any age (e.g. [k] replaced by $[\mathrm{m}])$. 
Table 8. Description of subjects - Experiment 2.

\begin{tabular}{lccccc}
\hline & Age range & Mean age & Boys & Girls & Total \\
\hline Age 2 & $2 ; 5-2 ; 11$ & $2 ; 7$ & 4 & 5 & 9 \\
\hline Age 3 & $3 ; 0-3 ; 10$ & $3 ; 5$ & 5 & 4 & 9 \\
\hline$<2 \mathrm{MLU}_{\mathrm{W}}$ & $2 ; 6-3 ; 0$ & $2 ; 8$ & 0 & 2 & 2 \\
\hline$>2 \mathrm{MLU}_{\mathrm{W}}$ & $2 ; 5-3 ; 10$ & $3 ; 1$ & 9 & 7 & 16 \\
\hline
\end{tabular}

children were recruited from the same region as in the previous experiments and they were tested within the same experimental settings as before.

The response rate for the direct object elicitation conditions was $95 \%$, and the response rate for the indirect object elicitation conditions was $65 \%$. While the response rate for indirect object clitics is substantially lower than for direct objects, it is nevertheless surprisingly good, given our concerns with the design of the task and the responses of adult controls within similar conditions (11\% clitic omissions).

\subsection{Results and discussion}

This section describes the results of the experiment, noting both the more general and the more specific patterns evident from the data. Table 9 gives the results, in raw numbers and in average percentages across children, broken down by the age of the subject (two year olds vs. three year olds) as well as by the $\mathrm{MLU}_{\mathrm{W}}$ of the subject $\left(\mathrm{MLU}_{\mathrm{W}}<2.0\right.$ vs. $\left.\mathrm{MLU}_{\mathrm{W}}>2.0\right)$.

An examination of the results reported in Table 9 makes it evident that these children do not show any problems producing either direct or indirect object clitics, exactly as expected, if Romanian is a Pattern II language. Thus, in this experiment Romanian two year olds are producing direct object clitics $86 \%$ of the time and indirect object clitics $82 \%$ of the time, which is comparable to the patterns

Table 9. Results - experiment 2.

\begin{tabular}{lllllllll}
\hline Romanian & \multicolumn{2}{l}{$\begin{array}{l}\text { Direct object } \\
\text { clitic (CV) }\end{array}$} & \multicolumn{2}{l}{$\begin{array}{l}\text { Direct object } \\
\text { omission }\end{array}$} & \multicolumn{2}{l}{$\begin{array}{l}\text { Indirect object } \\
\text { clitic (CV) }\end{array}$} & \multicolumn{2}{l}{$\begin{array}{l}\text { Indirect object } \\
\text { omission }\end{array}$} \\
\hline Age 2 N=9 & $76 / 88$ & $\begin{array}{l}86 \% \\
(0.28)\end{array}$ & $12 / 88$ & $14 \%$ & $114 / 133$ & $\begin{array}{l}82 \% \\
(0.39)\end{array}$ & $19 / 133$ & $18 \%$ \\
\hline Age 3 N=9 & $73 / 86$ & $\begin{array}{l}86 \% \\
(0.36)\end{array}$ & $13 / 86$ & $14 \%$ & $101 / 122$ & $\begin{array}{l}74 \% \\
(0.54)\end{array}$ & $21 / 122$ & $26 \%$ \\
\hline$<2 \mathrm{MLU}_{\mathrm{W}} \mathrm{N}=2$ & $3 / 19$ & $\begin{array}{l}16 \% \\
(1.44)\end{array}$ & $16 / 19$ & $84 \%$ & $0 / 15$ & $\begin{array}{l}0 \% \\
(0)\end{array}$ & $15 / 15$ & $100 \%$ \\
\hline$>2 \mathrm{MLU}_{\mathrm{W}} \mathrm{N}=16$ & $146 / 155$ & $\begin{array}{l}94 \% \\
(0.12)\end{array}$ & $9 / 155$ & $6 \%$ & $215 / 240$ & $\begin{array}{l}87 \% \\
(0.28)\end{array}$ & $25 / 240$ & $13 \%$ \\
\hline
\end{tabular}


reported for Pattern II languages, such as Spanish and Greek, but not Pattern I languages, such as Catalan, Italian, and French (at least for direct object clitics, where data are available for comparison). A similar pattern is observed for three year olds, with one - rather surprising - exception, an indirect object clitic response rate that is lower than that of two year olds ( $74 \%$ vs. $82 \%$ ). Note that neither group of children has provided any full DP answers in place of the expected clitics, a pattern that further strengthens our conclusion that Romanian is a Pattern II language, so that Romanian children encounter no grammatical problems in acquiring and producing indirect object clitics.

It may seem surprising that in this experiment three year olds performed slightly worse than two year olds. However, if children are grouped on the basis of $\mathrm{MLU}_{\mathrm{W}}$, rather than age, we observe less group variability (expressed in terms of coefficient of variability) for the large group, suggesting a better fit, i.e. a more natural grouping. ${ }^{18}$ Thus, children unable to produce utterances of the length required by the clitic constructions ( 2 words) independently of the clitic elicitation task, omit direct object clitics $84 \%$ of the time and indirect object clitics $100 \%$ of the time. Children able to produce utterances of the length required by the clitic constructions omit clitics only $6 \%-13 \%$ of the time. ${ }^{19}$

Although Romanian children are producing both direct and indirect objects at rates that suggest that they have no particular problems with these constructions, it is noticeable that overall they are performing slightly worse with indirect object clitics than direct object clitics, regardless of whether they are grouped by age or MLU, and that indirect object clitic production is more variable than direct object clitic production across subjects. Thus, children are producing indirect object clitics $4 \%-16 \%$ less than direct object clitics, and variability is around $0.1(10 \%)$ higher for indirect objects than for direct objects. Also, an examination of individual responses (provided in Appendix II), suggests that children who produce direct object clitics successfully also produce indirect object clitics successfully, although they tend to produce correct indirect object clitics less frequently than direct object clitics.

Of course, it is still necessary to determine whether this pattern is due to developmental order, with direct object clitics being acquired earlier than indirect object clitics, or the nature of the experimental task coupled with the special properties of the indirect object clitic construction not shared by the direct object clitic construction. Available data from adult controls suggest that the latter, rather than the

18. The observed high variability of the group whose $\mathrm{MLU}_{\mathrm{W}}$ is under 2 is expected given the low number of children in this group ( 2 children).

19. In the indirect object elicitation experiment adult controls produced the direct object as a clitic $6.7 \%$ of the time, as a definite DP $59.2 \%$ of the time, and as an indefinite DP $34.1 \%$ of time; children produced the direct object as a clitic $20.9 \%$ of the time, as a definite DP $25.3 \%$ of the time, as an indefinite DP $20.9 \%$, dropped it $21.7 \%$ of the time, and used a non-target structure $11.2 \%$ of the time. Note that given the choice of verbs and the discourse conditions created in the experiment, omission of the direct object did not lead to ungrammaticality, so that these numbers are not a reflection of the children's mastery of direct objects or accusative clitic constructions, which children actually produced at a higher rate than adults in this particular experimental context. 
former, hypothesis provides the most likely explanation for the observed pattern. In other words, the indirect object clitic production is lower than direct object clitic production not because of some developmental lag, but rather, because of the peculiarities of the indirect object construction and of the elicitation task. Thus, while adult controls produced direct object clitics $100 \%$ of the time, they produced indirect object clitics only $89 \%$ of the time: the four adult controls that were used in the indirect object clitic task ranged between $80 \%$ - 94\% indirect object clitic production. Notably, one of the controls in this task also acted as a control in the direct object clitic elicitation experiment, producing $100 \%$ direct object clitics but only $80 \%$ indirect object clitics. Therefore, it is likely that some discourse or task-related factor allowed adults to produce the targeted verbs without an indirect object clitic and that the same factor interfered with children's indirect object clitic production, causing the observed difference in successful production between direct and indirect object clitics. However, it is important to note that this approach explains why children with $\mathrm{MLU}_{\mathrm{W}}$ greater than 2 produce indirect object clitics $87 \%$ of the time (comparable to the $89 \%$ produced by the adult controls) and not $95 \%$ of the time as with the direct object clitics. It does not explain why children with $\mathrm{MLU}_{\mathrm{W}}$ lower than 2 produce $0 \%$ indirect object clitics. As we have argued above, the pattern observed with this $\mathrm{MLU}_{\mathrm{W}}$ group must be explained by their production limitation.

Thus, a comparison of the group of children who can successfully produce utterances of two or more words with the adult controls shows that this group of children performs in an adult-like fashion, producing both direct and indirect object clitics, which suggests that there is no grammatical constraint that prevents them from producing clitics. However, just as with adults, there might be additional task- or discourse-related factors that prevent children from producing indirect object clitic responses at the same rate as direct object clitic responses. ${ }^{20}$ On the other hand, children who are unable to produce utterances of the length required by the target constructions are also unable to produce clitic responses, which would require more words than they are capable of producing at one time.

Finally, let us discuss the differences in response patterns attributable to the variables we controlled for: the type of argument that was elicited and the type of question used to elicit the target responses.

With respect to the differences among responses containing Goal, Benefactive and Possessive arguments, it is not possible to determine whether this manipulation affected the response pattern or not. This is because children often replaced the target verb with a verb requiring an indirect object argument of a different type.

20. Note that the responses lacking an indirect object clitic (which the children and, occasionally, the adults produced) are ungrammatical according to the standard prescriptive grammar of Romanian and have been judged to be unacceptable by two native speakers of Romanian from the same region as the children, who formed these judgments on the basis of transcripts of the experiment. Despite the unacceptability of these constructions in normative Romanian, something in the set-up of the experimental task (perhaps, the richness of the discourse context or the casual register of speech being used) allowed the adult controls to occasionally omit the indirect object clitics, so that we may expect the children who have mastered the construction to perform similarly under the same conditions. 
For instance, verbs taking a Benefactive were often replaced by the verb 'give', which requires a Goal argument. Such a substitution typically resulted in an appropriate description of the action: although the target phrase 'frying sausages for a boy' might be the most appropriate description of the event that had been acted out, the replacement phrase frequently produced by the children - 'giving sausages to the boy' - is not, strictly speaking, inaccurate, for sausages that have been fried for the boy are likely to be given to him, as well. Given extensive replacements of this type encountered in the responses, it was not possible to determine if the children preferred one type of dative arguments to another. Furthermore, while children generally replaced Benefactive or Possessive verbs with Goal verbs (such as 'give', 'take', and 'make'), it is not clear that this strategy was due to their preference for Goal arguments, rather than the higher frequency of these verbs in children's production, the higher saliency of Goal arguments compared to other types of dative arguments, or the fact that in most cases a Benefactive or Possessive action can be viewed as a subset of a Goal action, as in the example discussed above. Thus, although our experiment controlled for the type of argument the indirect object clitic was expressing, we cannot draw any conclusions about the children's performance with the distinct types of arguments at this time. Furthermore, given the difficulties with eliciting and interpreting these data discussed above, this is likely to remain an extremely difficult task for future experiments as well.

With respect to the type of question that elicited the indirect object clitic, most children produced an answer of the required type when the experimenter used the question format of Step 1 (i.e., a question that did not use the target clitic), so that very few responses had to be elicited using the question format of Step 2 (i.e., a question that used the target clitic). Out of all of the indirect object clitic constructions produced by the children, $83 \%$ were produced as a response to a Step 1 question, and only $17 \%$ were produced as a response to a Step 2 question. Therefore, it seems that while the response rate was improved by the use of Step 2 questions, at least to some extent, the numbers reported above (see Table 11) cannot be viewed as the outcome of imitation made possible by the presence of the targeted clitic in the elicitation question.

\section{Discussion}

In this paper, we have offered evidence for three general points. First, utilizing the results of three elicited production experiments, we have demonstrated that early Romanian exhibits Pattern II of clitic acquisition, so that object clitics are not problematic for young children and are produced freely in obligatory environments. Second, we have developed an explanation for the pattern of object clitic acquisition in early Romanian, based on the UCC Hypothesis. We have argued that clitic omissions shown by very young Romanian children are not comparable to the UCC-related omissions observed in Pattern I languages; rather, they are due to a production limitation, that is, the inability of very young children to produce utterances of the length required by the clitic constructions. In support of this point we have demonstrated that MLUs are a much more reliable predictor of the children's 
performance than age. Third, we have expanded our field of inquiry to include the acquisition of indirect object clitics, demonstrating that the predictions of our theory are confirmed for these elements as well, that is, that early Romanian exhibits Pattern II in the acquisition of the indirect object clitics, as well. We conclude that, although somewhat challenging in terms of elicitation, indirect object clitics can be an extremely informative and valuable object of study.

\section{Appendix I: Experimental items}

Verbs used in Direct Object Clitic Elicitation - Experiment 1 (all are different transitive verbs in Romanian):

\section{Present masculine definite NP}

Mother-pig pets the piglet

Experimenter dresses the baby

The doctor check (with stethoscope) the baby

Experimenter pastes the eye - inanimate

\section{Past masculine definite NP}

The girl hid the mouse

Stitch shot the bandit

The dinosaur swallowed the snake

The boy broke the chair- inanimate

\section{Present feminine definite NP}

Experimenter combs the doll

Experimenter shoes the girl

The mother rocks the girl

The girl presses the dress - inanimate

\section{Past feminine definite NP}

The doctor bandaged the frog

The robot hit the girl

The elephant stepped on the lizard

The boy broke the vase - inanimate

\section{Present masculine proper name}

The girl tickles Tweety

Experimenter undresses Daffy Duck

The dinosaur pushes Winnie

Experimenter shaves Santa Claus.

\section{Past masculine proper name}

The elephant sprinkled Mr. M

The doctor operated on Sylvester

The cat scratched Scooby

The bee stung Snoopy

\section{Present feminine proper name}

Experimenter washes Barbie

Experimenter dries Barbie

Experimenter sews Kitty

The prince kisses Snow White

Past feminine proper name

The wolf ate Red Riding Hood

The frog painted Milka

Experimenter made-up Barbie

The hunter saved Red Riding Hood

\section{Verbs used in Indirect Object Clitic Elicitation - Experiment 2}

Goal

The boy gave a present to the girl-F.

The grand-daughter brought a glass of water to the grandmother-F.

The vending girl sold an/the ice cream to the boy-M.

Mother sang a song to the baby-M.

Johnny threw the ball to Mary-F.

Experimenter put ear-rings to the girl-F.

The girl sent a letter to the boy-M. 


\section{Benefactive}

Granny knitted a hat for the little girl-F.

Experimenter fried some potatoes for the boy-M.

Experimenter packed clothes for the boy-M.

Experimenter peeled an orange for the girl-F.

Experimenter cut a slice of pizza for the girl-F.

Experimenter made a sandwich for the boy-M.

Mother bought a bike for the boy-M.

\section{Possessive}

The doctor pulled the boy's-M tooth.

The boy broke the girl's-F doll.

Experimenter braided the girl's-F hair.

The boy soiled the girl's-F blouse.

The robot broke the boy's-M hand.

The cat stole the dog's-M bone.

The craftsman repaired the girl's-F doll.

\section{Appendix II. Individual responses from Experiment 2}

Table i. Individual responses.

\begin{tabular}{|c|c|c|c|c|c|c|c|c|}
\hline \multirow[t]{2}{*}{ Child } & \multicolumn{3}{|l|}{ MLU } & \multicolumn{2}{|c|}{ Accusative } & \multicolumn{3}{|c|}{ Dative } \\
\hline & Story & Imitation & MLU & $\begin{array}{c}\text { Clitic } \\
\text { response }\end{array}$ & $\begin{array}{c}\text { Full } \\
\text { DP }\end{array}$ & $\begin{array}{c}\text { Clitic } \\
\text { omission }\end{array}$ & $\begin{array}{c}\text { Clitic } \\
\text { response }\end{array}$ & $\begin{array}{c}\text { Clitic } \\
\text { omission }\end{array}$ \\
\hline M 2;5 & 1.75 & 2.88 & 2.32 & $10(100 \%)$ & 0 & 0 & $16(94 \%)$ & $1(6 \%)$ \\
\hline A $2 ; 6$ & 2.67 & $\mathrm{n} / \mathrm{a}$ & 2.67 & $9(90 \%)$ & 0 & $1(10 \%)$ & $12(86 \%)$ & $2(14 \%)$ \\
\hline I $2 ; 6$ & 3.41 & 2.88 & 3.15 & $6(60 \%)$ & 0 & $4(40 \%)$ & $13(93 \%)$ & $1(7 \%)$ \\
\hline L $2 ; 6$ & 2.13 & 1 & 1.57 & $3(33 \%)$ & 0 & $6(67 \%)$ & 0 & $9(100 \%)$ \\
\hline R 2;6 & 3.41 & 1 & 2.21 & $10(100 \%)$ & 0 & 0 & $15(100 \%)$ & 0 \\
\hline V 2;9 & 3.07 & 5.6 & 4.34 & $10(100 \%)$ & 0 & 0 & $13(76 \%)$ & $4(24 \%)$ \\
\hline C $2 ; 10$ & 3.05 & 6.52 & 4.79 & $9(100 \%)$ & 0 & 0 & $18(100 \%)$ & 0 \\
\hline R $2 ; 10$ & 3.80 & 7.16 & 5.5 & $9(90 \%)$ & 0 & $1(10 \%)$ & $10(91 \%)$ & $1(9 \%)$ \\
\hline L 2;11 & 4.71 & 6.76 & 5.74 & $10(100 \%)$ & 0 & 0 & $17(95 \%)$ & $1(5 \%)$ \\
\hline A $3 ; 0$ & 2.25 & 1.29 & 1.77 & 0 & 0 & $10(100 \%)$ & 0 & $6(100 \%)$ \\
\hline A $3 ; 3$ & 2.69 & $\mathrm{n} / \mathrm{a}$ & 2.69 & $10(100 \%)$ & 0 & 0 & $12(100 \%)$ & 0 \\
\hline M 3;3 & 3.07 & 1.16 & 2.12 & $10(100 \%)$ & 0 & 0 & $15(94 \%)$ & $1(6 \%)$ \\
\hline C $3 ; 4$ & 2.77 & 1.59 & 2.18 & $9(90 \%)$ & 0 & $1(10 \%)$ & 0 & $9(100 \%)$ \\
\hline A $3 ; 6$ & 4.06 & 6.72 & 5.39 & $10(100 \%)$ & 0 & 0 & $16(89 \%)$ & $2(11 \%)$ \\
\hline S 3;6 & 4.03 & 4.71 & 4.37 & $7(100 \%)$ & 0 & 0 & $12(92 \%)$ & $1(8 \%)$ \\
\hline V 3;6 & 3.19 & 2.12 & 2.66 & $8(80 \%)$ & 0 & $2(20 \%)$ & $16(89 \%)$ & $2(11 \%)$ \\
\hline A $3 ; 8$ & 4.28 & 7.12 & 5.7 & $10(100 \%)$ & 0 & 0 & $15(100 \%)$ & 0 \\
\hline R $3 ; 10$ & 4.29 & 7.80 & 6.05 & $9(100 \%)$ & 0 & 0 & $15(100 \%)$ & 0 \\
\hline
\end{tabular}


Table ii. Type of question eliciting an indirect clitic response.

\begin{tabular}{lccc}
\hline & $\begin{array}{c}\text { Step 1 indirect } \\
\text { object clitic response }\end{array}$ & $\begin{array}{c}\text { Step 2 indirect } \\
\text { object clitic response }\end{array}$ & $\begin{array}{c}\text { Total indirect } \\
\text { object clitic response }\end{array}$ \\
\hline M 2;5 & $15(94 \%)$ & $1(6 \%)$ & 16 \\
\hline A $2 ; 6$ & $10(83 \%)$ & $2(17 \%)$ & 12 \\
\hline I 2;6 & $12(92 \%)$ & $1(8 \%)$ & 13 \\
\hline R 2;6 & $14(93 \%)$ & $1(7 \%)$ & 15 \\
\hline V 2;9 & $9(69 \%)$ & $4(31 \%)$ & 13 \\
\hline C $2 ; 10$ & $7(39 \%)$ & $11(61 \%)$ & 18 \\
\hline R 2;10 & $9(90 \%)$ & $1(10 \%)$ & 17 \\
\hline L 2;11 & $15(88 \%)$ & $2(12 \%)$ & 15 \\
\hline A 3;3 & $11(92 \%)$ & $1(8 \%)$ & 16 \\
\hline M 3;3 & $13(87 \%)$ & $2(13 \%)$ & 12 \\
\hline A 3;6 & $14(88 \%)$ & $2(12 \%)$ & 16 \\
\hline S 3;6 & $9(75 \%)$ & $3(25 \%)$ & 15 \\
\hline V 3;6 & $14(88 \%)$ & $2(12 \%)$ & $205(100 \%)$ \\
\hline A 3;8 & $12(80 \%)$ & $3(20 \%)$ & 15 \\
\hline R 3;10 & $14(93 \%)$ & $37(17 \%)$ & 12 \\
\hline Total & $168(83 \%)$ & & 15 \\
\hline
\end{tabular}

\section{References}

Anderson, Raquel T. (1998). «The development of grammatical case distinctions in the use of personal pronouns by Spanish-speaking preschoolers». Journal of Speech, Language and Hearing Research 41: 394-411.

Arlman-Rupp, A. J. L.; van Niekerk de Haan, D.; van de Sandt-Koenderman, Mieke (1976). «Brown's early stages: Some evidence from Dutch». Journal of Child Language 3: 267-274.

Avram, Larisa (1999). «Clitic omission in child language and Multiple Spell-Out». Poster presented at Gala 1999, University of Potsdam.

Babyonyshev, Maria; Marin, Stefania (2004a). «The acquisition of object clitic constructions in Romanian». Talk presented at The Second Lisbon Meeting on Language Acquisition. University of Lisbon, Lisbon, Portugal.

- (2004b). «Object clitics in child Romanian». In: Brugos, Alejna; Clark-Cotton, Manuella R.; Ha, Seungwan (eds.). BUCLD 29: Proceedings of the $29^{\text {th }}$ annual Boston University Conference on Language Development. Cascadilla Press, Cambridge, MA, pp. 49-60.

- (To appear). «The Acquisition of Object Clitic Constructions in Romanian». In: Gess, Randall S.; Rudin, Edward (eds.). Theoretical and Experimental Approaches to Romance Linguistics. Selected papers from the 34th Linguistic Symposium on 
Romance Languages (LSRL), Salt Lake City, March 2004. Amsterdam: John Benjamins.

Blasco, Maria (2000). The Acquisition of Pronominal Object Clitics in Spanish. CUNY, doctoral dissertation.

Bottari, Piero; Cipriani, Paola; Chilosi, Ana Maria (1993/1994). «Protosyntactic devices in the acquisition of Italian free morphology». Language Acquisition: A Journal of Developmental Linguistics 3: 327-369.

Day, Alexandra (1991). Carl's Afternoon in the Park. New York: Farrar Straus Giroux. Friedemann, Mark-Ariel (1993/94). «The Underlying Position of External Arguments in French: A Study in Adult and Child Grammar». Language Acquisition 3: 209-255.

Guasti, Maria Teresa (1993/94). «Verb syntax in Italian child grammar: Finite and nonfinite verbs». Language Acquisition 3: 1-40.

Hamman, Cornelia; Rizzi, Luiggi; Frauenfelder, Uli H. (1996). «On the acquisition of the pronominal system in French». In: Clahsen, Harald (ed.). Generative Perspectives on Language Acquisition. Amsterdam: John Benjamins, pp. 309-334.

Hickey, Tina (1991). «Mean length of utterance and the acquisition in Irish». Journal of Child Language 18: 553-569.

Jakubowicz, Celia; Nash, Lea; Rigaut, Catherine; Gerard, Christophe-Loic (1998). «Determiners and Clitic Pronouns in French-speaking Children with SLI». Language Acquisition 7: 113-160.

Kayne, Richard (1989). «Facets of Romance Past Participle Agreement». In: Beninca, Paola (ed.). Dialect Variation and the Theory of Grammar. Dordrecht: Foris, pp. 85-103.

Lyzckowski, David (1999). Adquieretelo: On the Acquisition of Pronominal Object Clitics in Spanish. Harvard University, undergraduate thesis.

Marin, Stefania (2004). «Pronominal Clitic Positioning is Morpho-Phonological: Evidence from Romanian Adult and Acquisition Data». Yale University, unpublished manuscript.

Schaeffer, Jeannette (2000). The Acquisition of Direct Object Scrambling and Clitic Placement. Amsterdam/Philadelphia: John Benjamins.

Sportiche, Dominique (1996). «Clitic constructions». In: Rooryck, Johan; Zaring, Laurie (eds.). Phrase Structure and the Lexicon. Dordrecht: Kluwer, pp. 213-276.

Templin, Mildred (1957). Certain Language Skills in Children. Minneapolis: University of Minnesota Press.

Tsakali, Vina; Wexler, Kenneth (2003). «Why children omit clitics in some languages but not in others: new evidence from Greek». In: van Kampen, Jacqueline; Baauw, Sergio (eds.). Proceedings of GALA 2003 (Generative Approaches to Language Acquisition) Volume 2. LOT (Netherlands Graduate School of Linguistics) Occasional Series.

Wexler, Kenneth (1998). «Very early parameter setting and the unique checking constraint: a new explanation of the optional infinitive stage». Lingua 106: 23-79.

- (2003). «The Unique Checking Constraint as the explanation of clitic omission in SLI and normal development». In: Jakubowicz, Celia; Nash, Lea; Wexler, Kenneth (eds.). Essays on Syntax, Morphology and Phonology in SLI. Cambridge, Mass: MIT Press.

Wexler, Kenneth; Torrens, Vicenç (1996). «Clitic Doubling in Early Spanish». In: Stringfellow, Andy; Cahana-Amitay, Dalia; Hughes, Elizabeth; Zukowski, Andrea 
(eds.). BUCLD 20: Proceedings of the $20^{\text {th }}$ annual Boston University Conference on Language Development. Cascadilla Press, Cambridge, MA, pp. 780-791.

Wexler, Kenneth; Gavarró, Anna; Torrens, Vicenç (2004). «Feature checking and object clitic omission in child Catalan and Spanish». In: Bok-Bennema, Reineke; Hollebrandse, Bart; Kampers-Manhe, Brigitte; Sleeman, Petra (eds.). Romance Languages and Linguistic Theory 2002: Selected papers from 'Going Romance', Groningen, 28-30 November 2002. Amsterdam: John Benjamins, pp. 253-269. 